\title{
The Effect of Music on the Attention and Memory of the Second- Grade Primary School Students with Learning Disorder in Ghaemshahr city
}

\author{
Seyyedeh Zhila Saber ${ }^{1}$, Babak Hosseinzadeh ${ }^{2}$ \\ ${ }^{1}$ PhD Student in Educational Psychology, Islamic Azad University of Babol. \\ ${ }^{2}$ Assistant Professor, Department of Educational Sciences, Islamic Azad University of Babol.
}

\begin{abstract}
ARTICLE INFO
Keywords:

Music usage, attention, active memory, learning disorder.
\end{abstract}

\begin{abstract}
The purpose of this study was to investigate the effect of Music Use on the Attention and memory of the second-grade primary school students with learning disorder in Ghaemshahr city. This study was applied in terms of purpose, and in terms of method, it was a quasiexperimental research with pre-test and post-test design with a control group. The population consisted of all second-grade primary school students with learning disorder in Ghaemshahr city, and due to the semi-experimental nature of the research, 30 subjects ( 15 in the experimental group and 15 in the control group) were selected as sample using simple random sampling. Data were collected using Stroop's Attention Test and Daneman \& Carpenter's (1980) Active Memory Test. Validity and reliability of the tools were confirmed. To analyze the data, multivariate analysis of covariance (MANCOVA) and single-variable analysis of covariance (ANCOVA) tests were used. The results showed that the use of music has a significant effect on the attention and memory of the secondgrade primary school students with learning disorder in Ghaemshahr. Therefore, the use of music can be effective in improving the attention and active memory of children with learning disorder.
\end{abstract}

\section{Introduction}

Learning disorder is one of the most important disorders in children psychiatry. Based on the fourth diagnostic-statistical manual of mental disorders, learning disorder is recognized when progress in standardized tests is significantly below expectation. This disorder is important because it disturbs the routine of schoolwork and daily tasks. It is said that $50 \%$ of students in the United States have at least one kind of learning disorder (Abbas Zzadeh et al., 2015). Learning disorder is a disturbance in one or more basic psychological processes that results in difficulty in understanding speech and writing. This disorder can be manifested in the form of complete inability in listening, thinking, speaking, writing, spelling, or performing mathematical calculations (Casey, 2012).

Memory and attention impairments are more pronounced in children who have difficulty in reading, writing, and math, and confront them with serious educational problems (Barzegar Beffrouie et al., 2015). Learning disorder is primarily affected by cognition. People have different 
cognitive functions such as attention and memory. Attention is the initial step in processing and considered as the ability to select a part of the environmental information for subsequent processing, and based on it, concentration and awareness (Karimi et al., 2011). On the other hand, active memory is a multi-axis cognitive system that enables individuals to maintain information in the presence of unrelated stimuli and manipulate information to achieve a targeted activity (Hassanzadeh and Ahmadi, 2015). The ability of active memory plays an important role in various aspects of life, including reading comprehension, writing, problem solving, mathematical reasoning, writting language and various behavioral domains (Swanson \& O'Connor, 2009; Schneider, 2015).

Considering that people with learning disorders have difficulty in cognitive functions such as attention and memory, therefore, the use of therapeutic methods in this field is effective. One of the therapeutic methods for increasing memory and concentration is the use of music. Scientists concluded that listening to music was a kind of exercise for practicing the effects of symmetrizing which is associated with the great activities of the mind. There is a relationship between cognition and music. Chiho and Chun (2003) consider systematically teaching music as effective in the field of memory processing. Collier and Logan (2000) also believe that short-term memory performance using acoustic rhythmic stimulation is better than when visual acuity is utilized (Pasha et al., 2010). Music through imagination leads to memory enhancement (Khalaf Beygy et al., 2006). When hearing music is only active hearing and is not accompanied by motion performance, cognitive reflections are more likely to be seen in the form of individual harmony and the absence of destructive or non-musical behaviors. There are several signs and symptoms that indicate that the special neural networks of music processing in the brain act completely autonomous and independent (of other neural structures of the brain). Strengthening and facilitating the performance of the networks involved in music in the left hemisphere (through early music education) increases the mental abilities of these areas, which include the components needed for reasoning (Karimi et al, 2011).

Ebrahimpour and Sajedi Rad (2017) in a study named "The effectiveness of music therapy on strengthening the auditory memory of slow-learning children" showed that music therapy has been effective in improving the memory performance of slow-learners in the post-test phase and has led to improved auditory memory among slow-learner students. In a research entitled "The effect of hearing music (rhythmic and melodic) on the auditory and visual attention and focus and social skills of preschool children", Zabihi et al. (2015 showed that listening to music affects the visual, auditory and social skills of preschool children. Also, the learning process cannot be done without the needed attention. Abbaszadeh et al. (2015), in a research entitled "The effectiveness of music therapy in improving reading and writing performance of students with learning disorders," showed that music therapy had an effect on reading disability. Music therapy had a significant effect on writing impairment in the fields of visual memory, auditory memory, and educational memory; however, it did not affect the accuracy level. Matloobi et al. (2014), in a research entitled "The effects of background music on auditory-verbal memory performance of students with normal hearing and speech abilities", showed that the average score of auditory-verbal memory tests was significantly higher in the silence position compared to two positions, one of which with positive emotional stimulating music and the other with neutral music. Arjmandnia et al. (2014), in an article entitled "The effectiveness of a cognitive computer training program on the performance of active visual-spatial memory of students with mathematical problems", which was conducted on the third- and fourth-grade primary school students with mathematical disorders in Tehran, found that computer-cognitive intervention had a significant effect on improving the active 
memory of students with mathematical problems in both the total score and the test subscales (maze memory and forward and backward cubes). Karimi et al. (2011), in a study entitled "The effects of music therapy on selective attention of children with Attention Deficit Hyperactivity Disorder (ADHD)", showed that the implementation of a music therapy program has a positive and significant effect on the selective attention of students with attention deficit hyperactivity disorder. Pasha et al. (2010), in a study entitled "The effects of active music on memory and attention of schizophrenic patients", showed that active music training has a positive and significant effect on sensory memory, active memory, long-term memory and attention of these patients. Kayhani et al. (2008), in a study entitled "Investigating the effects of music on attention performance of students of Islamic Azad University of Medical Sciences in Tehran", showed that listening to music could improve memory and attention performance. Christopher and Shelton (2017), in a research entitled "Individual differences in work memory: predicting the impact of music on students' performance", showed that working memory capacity moderates the harmful effects of music on academic performance. Avila et al. (2012) also investigated the effect of music on the performance of introverted and extraverted individuals by the use of a verbal, numerical and logical test with three different fields of vocal, instrumental and silent music showed that, in verbal testing, all participants had a considerably better performance in the silence, and concluded that poetry with verbal information processing interfere with introverted and extraverted individuals.

Given the fact that music as one of the therapeutic methods has an impact on improving the performance of children with special disorders, such as learning disorder, also considering the therapeutic importance of using music in clinical clinics in Iran, and knowing that a few research has been conducted in the cognitive area of active memory and attention of children with learning disorder, the purpose of the present study was to investigate the effects of music usage on active memory and attention of the second-grade primary school children with learning disorders in Ghaemshahr city. To achieve this general goal, the following hypotheses are proposed:

1. Using music affects the attention of the second-grade primary school children with learning disorders in Ghaemshahr city.

2. Using music affects the active memory of the second-grade primary school children with learning disorders in Ghaemshahr city.

\section{Research Methodology}

The present research is applied in terms of purpose and is a semi-experimental study with pre-test and post-test design with control group in terms of subject nature and research objectives. The population consisted of all second-grade primary school students with learning disorders in Ghaemshahr city who had referred to the learning disorder centers of Department of Education in Ghaemshahr; and due to the semi-experimental nature of the research, 30 subjects (15 persons in the experimental groups and 15 persons in the control group) were selected as sample by simple random sampling method. This research was conducted in two groups of participants (experimental and control), who were measured two times. For this end, first, for both groups, a pretest (active memory and attention test) was performed and then, for the experimental group, the music program based on Orff Schulwerk theory was performed in 8 sessions of 30 minutes in a group form and once a week, but the control group did not receive any programs. At the end, the post-test (active memory and attention test) were performed for both groups. The data gathering tools in this research were: 
1. Stroop's Attention Test: This test was developed by Stroop in 1935 to evaluate specific attention and cognitive flexibility. This test consists of four cards, and in this research, the fourth card was used, in which the participants' reaction time and the number of errors are recorded. The reliability of this test was calculated equal to 0.71 by Alilou et al. (2011) using retest method. Its validity was also confirmed by Alilou et al. (2011);

2. Daneman and Carpenter's (1980) Active Memory Test: This test consists of 27 sentences and two dimensions (mental processing and mental storage), which were arranged in six sections, from two-sentence parts to seven-sentence parts. In this test, participant is asked to do two tasks simultaneously and in the following order: a) correctly identify the meaning of the sentences expressed (mental processing); b) remember the last word expressed in the sentences (mental storage). The reliability of this test was calculated equal to 0.88 by Asadzadeh (2009) using Cronbach's alpha coefficient. Its validity was also confirmed by Asadzadeh (2009).

3. Orff Music Instruments: Orff music instruments are divided into two categories: 1) ragtime melodic instruments which are played by plectrum have a certain and constant sound and music is played with it; in this study, bell music is used; 2) ragtime non-melodic instruments that have indeterminate sounds and are used to create rhythm and color of musical pieces. To analyze the data, the mean and standard deviation were used in the descriptive statistics section, and multivariate analysis of covariance (MANCOVA) and single variable analysis of covariance (ANCOVA) were used in the inferential statistics section. Data analysis was done using SPSS20 software.

\section{Findings}

The results related to the descriptive statistics (mean and standard deviation) of two groups of control and experimental in the pretest and posttest conditions are presented in table 1.

Table 1: Mean and standard deviation of the variables for the control and experimental groups

\begin{tabular}{|c|c|c|c|c|c|c|}
\hline Variable & Group & Test type & Number & Mean & $\begin{array}{l}\text { Standard } \\
\text { deviation }\end{array}$ & $\begin{array}{l}\text { Mean difference between } \\
\text { pretest and posttest }\end{array}$ \\
\hline \multirow{4}{*}{$\begin{array}{l}\text { Attention based } \\
\text { on reaction time }\end{array}$} & \multirow[b]{2}{*}{ Experimental } & Posttest & 15 & 41.266 & 3.918 & \multirow[b]{2}{*}{-0.5} \\
\hline & & Pretest & 15 & 36.266 & 6.284 & \\
\hline & \multirow{2}{*}{ Control } & Posttest & 15 & 40.066 & 6.169 & \multirow{2}{*}{0.2} \\
\hline & & Pretest & 15 & 40.266 & 7.274 & \\
\hline \multirow{4}{*}{$\begin{array}{l}\text { Attention based } \\
\text { on number of } \\
\text { errors }\end{array}$} & \multirow{2}{*}{ Experimental } & Posttest & 15 & 3.266 & 1.032 & \multirow{2}{*}{-1.4} \\
\hline & & Pretest & 15 & 1.866 & 1.302 & \\
\hline & \multirow{2}{*}{ Control } & Posttest & 15 & 3.133 & 1.125 & \multirow{2}{*}{0.067} \\
\hline & & Pretest & 15 & 3.2 & 1.014 & \\
\hline \multirow{4}{*}{$\begin{array}{l}\text { Mental } \\
\text { processing }\end{array}$} & \multirow{2}{*}{ Experimental } & Posttest & 15 & 13.933 & 3.75 & \multirow{2}{*}{4.067} \\
\hline & & Pretest & 15 & 18 & 4.208 & \\
\hline & \multirow{2}{*}{ Control } & Posttest & 15 & 12.8 & 2.426 & \multirow{2}{*}{0.2} \\
\hline & & Pretest & 15 & 13 & 2.203 & \\
\hline \multirow{4}{*}{ Mental storage } & \multirow{2}{*}{ Experimental } & Posttest & 15 & 11.133 & 3.356 & \multirow{2}{*}{4.933} \\
\hline & & Pretest & 15 & 16.066 & 3.305 & \\
\hline & \multirow{2}{*}{ Control } & Posttest & 15 & 11.8 & 1.698 & \multirow{2}{*}{0.085} \\
\hline & & Pretest & 15 & 11.885 & 1.859 & \\
\hline \multirow{4}{*}{ Active memory } & \multirow{2}{*}{ Experimental } & Posttest & 15 & 25.066 & 6.584 & \multirow{2}{*}{9} \\
\hline & & Pretest & 15 & 34.066 & 6.064 & \\
\hline & \multirow{2}{*}{ Control } & Posttest & 15 & 24.6 & 3.418 & \multirow{2}{*}{0.2} \\
\hline & & Pretest & 15 & 24.8 & 3.233 & \\
\hline
\end{tabular}


The results of table 1 show that the difference of the average scores of pretest and posttest in the variable of participant's attention based on reaction time was -0.5 and 0.2 in the experimental group and control group, respectively. In the variable of participant's attention based on the number of errors, the difference of the average scores of pretest and posttest was -1.4 and 0.067 in the experimental group and control group, respectively; in the variable of mental processing, it was 4.067 and 0.2 in the experimental group and control group, respectively; in the variable of mental storage, it was 4.933 and 0.085 in the experimental group and control group, respectively, and in the variable of active memory, it was 9 in the experimental group and 0.2 in the control group.

Hypothesis 1: Using music affects the attention of the second-grade primary school students with learning disorder in Ghaemshahr.

Table 2: The results of Levine test for investigating the variance sameness

\begin{tabular}{|l|c|c|c|c|}
\hline \multicolumn{1}{|c|}{ Variables } & $\begin{array}{c}\mathrm{F} \\
\text { Statistic }\end{array}$ & $\begin{array}{c}\text { First Freedom } \\
\text { Degree }\end{array}$ & $\begin{array}{c}\text { Second Freedom } \\
\text { Degree }\end{array}$ & $\begin{array}{c}\text { Significance } \\
\text { Level }\end{array}$ \\
\hline Attention based on reaction time & 3.712 & 1 & 28 & 0.059 \\
\hline $\begin{array}{l}\text { Attention based on the number of } \\
\text { errors }\end{array}$ & 3.442 & 1 & 28 & 0.064 \\
\hline
\end{tabular}

According to table 2, since in the confidence level 0.95 and measurement error $\alpha=0.05$, the significance level for all variables has been obtained higher than $0.05(\mathrm{P}>0.05)$, the difference of variances is not statistically significant and the assumption that variances are equal is true. Therefore, the multivariate analysis of covariance (MANCOVA) test can be used.

Table 3: The results of analysis of covariance (MANCOVA) test

\begin{tabular}{|l|c|c|c|c|c|c|}
\hline \multicolumn{1}{|c|}{ Test } & Value & F statistic & $\begin{array}{c}\text { Freedom } \\
\text { degree of } \\
\text { group }\end{array}$ & $\begin{array}{c}\text { Error } \\
\text { freedom } \\
\text { degree }\end{array}$ & $\begin{array}{c}\text { Significance } \\
\text { level }\end{array}$ & Eta square \\
\hline Peyla's effect test & 0.478 & 11.457 & 2 & 25 & 0.000 & 0.478 \\
\hline Wilks's lambda test & 0.522 & 11.457 & 2 & 25 & 0.000 & 0.478 \\
\hline Hetling's effect test & 0.917 & 11.457 & 2 & 25 & 0.000 & 0.478 \\
\hline Roy's largest root test & 0.917 & 11.457 & 2 & 25 & 0.000 & 0.478 \\
\hline
\end{tabular}

According to table 3, since in the confidence level 0.95 and the measurement error $\alpha=0.05$, the significance level of all tests has been less than $0.05(\mathrm{P}<0.05 ; \mathrm{F}=11.457)$, there is a significance difference between the two groups at least in one of the test variables (attention based on reaction time attention based on the number of errors). Therefore, the null hypothesis is rejected and the research hypothesis is confirmed; thus it can be concluded that "using music has a significant impact on the attention of the second-grade primary school students with learning disorder". In other words, using music leads to the participant's decreased reaction time and number of errors; i.e. using music improves the attention of children with learning disorder. Considering the coefficient of eta, the level of using music effect on the attention of children with learning disorder is 0.478 .

Hypothesis 2: Using music affects the active memory of the second-grade primary school students with learning disorder. 
Table 4: The results of Levine test for investigating the variance sameness

\begin{tabular}{|c|c|c|c|c|}
\hline Variable & F statistic & $\begin{array}{c}\text { First freedom } \\
\text { degree }\end{array}$ & $\begin{array}{c}\text { Second freedom } \\
\text { degree }\end{array}$ & $\begin{array}{c}\text { Significance } \\
\text { level }\end{array}$ \\
\hline Active memory & 3.994 & 1 & 28 & 0.054 \\
\hline
\end{tabular}

According to table 4, sine in the confidence level 0.95 and the measurement error $\alpha=0.05$, the significance level is higher than 0.05 ( $\mathrm{P}>0.05$ ), the difference of variances is not statistically significant and the assumption that variances are equal is correct; therefore, the single variable analysis of covariance (ANCOVA) test can be used.

Table 5: The results of the single variable analysis of covariance (ANCOVA)

\begin{tabular}{|l|c|c|c|c|c|c|}
\hline $\begin{array}{c}\text { Source of } \\
\text { changes }\end{array}$ & $\begin{array}{c}\text { Sum of } \\
\text { squares }\end{array}$ & $\begin{array}{c}\text { Freedom } \\
\text { degree }\end{array}$ & $\begin{array}{c}\text { Mean of } \\
\text { squares }\end{array}$ & F statistic & $\begin{array}{c}\text { Significance } \\
\text { level }\end{array}$ & $\begin{array}{c}\text { Impact } \\
\text { level }\end{array}$ \\
\hline Pretest & 346.531 & 1 & 346.531 & 29.721 & 0.000 & 0.524 \\
\hline Group & 599.995 & 1 & 599.995 & 51.46 & 0.000 & 0.656 \\
\hline Error & 314.803 & 27 & 11.659 & & & \\
\hline Total & 27295.000 & 30 & & & & \\
\hline
\end{tabular}

According to table 5, since in the confidence level 0.95 and the measurement error 0.05 , the significance level of each group is less than $0.05(\mathrm{P}<0.05 ; \mathrm{F}=51.46)$, the average scores of the variable "active memory" is significantly higher in the experimental group than the control group in the posttest. Thus, the null hypothesis is rejected and the research hypothesis is confirmed; and it can be concluded that "Using music affects the active memory of the second-grade primary school students with learning disorder". In other words, using music improves the active memory of children with learning disorder. The level of using music effect on the active memory of children with learning disorder is 0.656 .

\section{Discussion and Conclusion}

Learning disorder is one of the most important disorders in children's psychiatry, which manifests itself in the form of complete inability to listen, think, speak, write, spell, or perform mathematical calculations, and mainly affect cognitive functions such as attention and memory. Therefore, in this research, the effect of music usage on the attention and memory of second-grade primary school students with learning disorder in Ghaemshahr city was studied. The results of this study showed that the use of music has a significant effect on the attention of second-grade primary school students with learning disorder in Qaemshahr city, and has reduced the reaction time and the number of errors in children with learning disorder. In other words, the use of music improves the attention of children with learning disorder. This finding is consistent with the results of Karimi et al. (2011), Pasha et al. (2010) and Kayhani et al. (2008). In explaining this finding, it can be said that musical and rhythmic sounds due to having rhythm and plectrum, which play an important role in understanding the time, increases individual's mental abilities and improves his/her attention.

Another finding of this study is that the use of music has a significant effect on the active memory of the second-grade primary school students with learning disorder in the city of Qaemshahr. That is, the use of music improves the memory of children with learning disorder. This finding is based on the results of Abrahampour and Sajedi Rad (2017), Abbaszadeh et al. (2015), Matloubi et al. 
(2014), Arjmandnia et al. (2014), Pasha et al. (2010), Kayhani et al. (2008) and Christopher and Shelton (2017). In explaining this finding, it can be said that, as Chiho and Chun (2003) argue, systematic teaching of music is effective in the memory processing. Music builds and strengthens the connections between neurons in the cortex, which is a process similar to that of evolution in the brain. In an environment with music, the inter-neuronal messenger circles are created, which stimulates the higher parts of the nervous system that is related to memory and cognition. Music is also one of the most important strategies that can improve the connection between the two brain hemispheres, because music is a weighted and harmonious regular tool, and the weight and harmony in it tend to increase the brain performance regularity of these students, reduce their cognitive problems, improve their learning, and have beneficial effects on memory and learning. In conclusion, based on the findings of the present study, it is suggested that officials of the Department of Education use music therapy to improve the attention and memory of children with learning disorder.

\section{References}

A. A. Arjmandnia, A. Sharifi, and R. Rostami, "The Effectiveness of Cognitive Computer Training Program on Active Visual-Spatial Memory Performance of Students with Mathematics Problems", Journal of Learning Disorders, Vol. 3, No. 4, 24-6, 2014.

Avila, C., Furnham, A., \& McClelland, A. (2012). The influence of distracting familiar vocal music on cognitive performance of introverts and extraverts. Psychology of Music. 40(2012). 84-93.

Casey, J.E. (2012). A model to guide the conceptualization, assessment, and diagnosis of Nonverbal Learning Disorder. Canadian Journal of School Psychology. 27(1). 35-57.

Chi Ho ,Y., \& Chun, M. (2003). Traning improves verbal but not visual memory: Cross-sectional and longitudinal explorations in children. Cheung Neuropsychology. 17(21003). 439-450.

Christopher, E.A., \& Shelton, J.T. (2017). Individual Differences in Working Memory Predict the Effect of Music on Student Performance. Journal of Applied Research in Memory and Cognition. 6(2).167-173.

Collier, G., \& Logan, G. (2000). Modality differences in short term memory for rhythms. Memory and Cognition. 28(2000). 529-538.

Gh. Pasha, S. Bakhtiarpour, G. Akhavan, "The Effects of Active Music on the Memory and Attention of Women with Schizophernia”, Scientific Quarterly of Women and Culture, Vol. 2, No. 5, 19-30, 2010.

H. Asadzadeh, "Investigating the Relationship between Active Memory Capacity and Academic Performance among the Third-Grade Secondary School Students in Tehran, Quarterly of Education", No. 1, 70-53, 2009.

K. Befrouei Barzgar, M. Mirjalili, and A. Shirjahani, "The Role of Motion Games, Painting and Music in Reducing the Behavioral-Educational Problems of Children with Learning Difficulties and Exceptional Education", Vol. 15, No. 7, 62-52, 2015.

L. S. Karimi, H, Zare, and H. Hadian Fard, "The Effects of music Therapy on the Selective Attention of Children with Attention Deficit Hyperactivity Disorder (ADHD)", Iranian Journal of Exceptional Children, Vol. 11, 44-33, 2011.

M. Ebrahimpour and T. Sajedi Rad, "The effectiveness of Music Therapy on the Strengthening the Auditory Memory of Slow-Learning Children, The Third International Conference on Psychology, Sociology”, Educational Sciences and Social Studies, Hall of Farhangian Conferences, Shiraz, 2017. 
M. Kayhani and M. Shariat pannahi, "Investigating the Effects of Music on the Focus and Attention of Students in Islamic Azad University of Medical Sciences in Tehran", Islamic Azad University Journal of Medical Sciences, Vol. 18, No. 2, 106-101, 2008.

M. KhalafBeigi, S. A. Bayanzadeh, A. Zad Mohammadi, and N. Shafaroudi, "The Effects of Musical Activities on the Memory of individuals with Schizophrenia, Iranian Journal of Clinical Psychiatry", (Thoughts and Behavior), Vol. 12, No. 46, 243-236, 2006.

S. Hassanzadeh and A. Ahmadi, "A Meta-Analysis on the Effectiveness of Intervention in Active Memory", Quarterly Journal of Applied-Psychological Studies, Vol. 6, No. 1, 46-25, 2015

S. Matloubi, A. Mohammad Zadeh, Z. Jafari, and A. Akbarzadeh Baghban, "The Effect of Background Music on the Performance of Auditory-Verbal Memory, Audiology Research Paper, Vol. 23, No. 5, 34-27, 2014.

Schneider, W. (2015). Memory Development from Early Childhood Through Emerging Adulthood. Springer International Publishing.

Swanson, H. L., \& O'Connor, R. (2009). The role of working memory and fluency practice on the reading comprehension of students who are dysfluent readers. Journal of Learning Disabilities. 42(6). 548-575. 